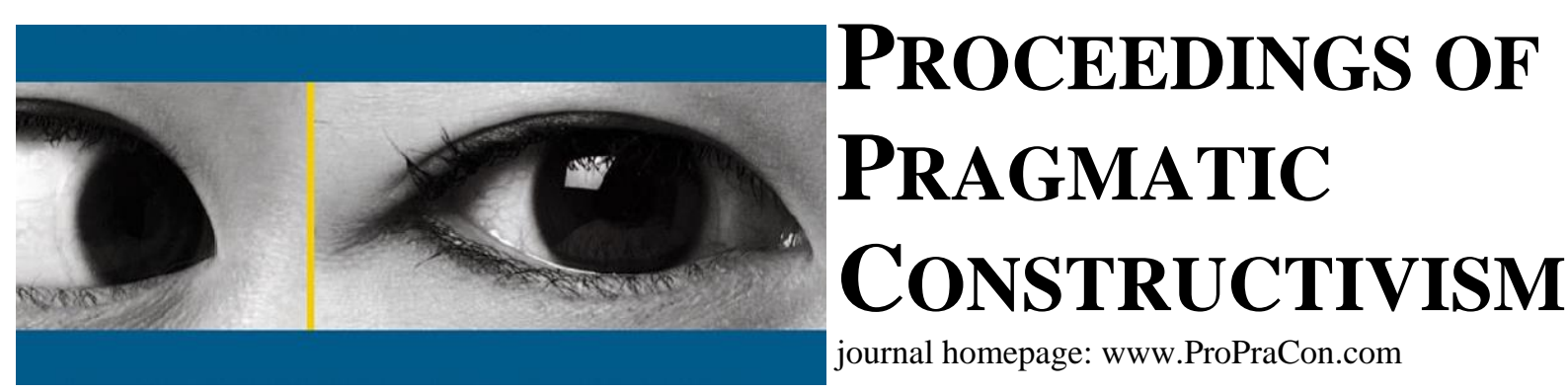

\title{
Social accounting in supply chain management: a pragmatic constructivist perspective
}

\author{
Daniela Pianezzi \\ Corresponding author \\ Scuola Superiore Sant'Anna; Institute of Management \\ Piazza Martiri della Libertà, 24; 56127 Pisa; Italy; danielapianezzi@gmail.com \\ Lino Cinquini \\ Professor of Management Accounting \\ Scuola Superiore Sant'Anna; Institute of Management \\ Piazza Martiri della Libertà, 24; 56127 Pisa; Italy; l.cinquini@sssup.it
}

Keywords: human rights, social accounting, pragmatic constructivism, supply chain.

\section{Purpose}

This study explores the role of accounting in the human rights management within the supply chain.Our interest for this issue arises from the recognition of significant changes occurred in the last decades. In today's global economy, "the competition has shifted more and more from an inter-firm to an inter-supply-chain level" (Gold et al., 2010) and many organizations are part of one or more supply chains (Samaranayake, 2005). As a result, "management processes now quite frequently transcend legal organizational boundaries" (Hopwood, 1996), as well as production processes. The financial crisis has emphasized the shift of power from nation states to transnational corporations at the centre of global value chains. These powerful actors are increasingly challenged by human rights violations occurring in the sociopolitical contexts in which they operate (Ruggie, 2007), especially where national law does not provide adequate protection. In these growing network systems, the main difficulty for a focal company is to exercise management control on suppliers over which it has no ownership, but for the behaviour of which it is held accountable (Andersen and Skjoett-Larsen, 2009). Indeed, in 2011, for the first time in the history, the UN Special Representative, John G. Ruggie, declared that corporations have direct human rights responsibilities, either through their own activities or as a result of their business relationships with other parties.

The main assumption of this study is that accounting can offer a valid support to prevent human rights violations in these complex organizational patterns. As underlined by Chetty (2011), «accounting can therefore play a key role in assisting business internalise human rights norms and evolve their business models to ones which actively contribute to "a social and international order" in which human rights can be realised». Accounting can be crucial in supporting the societal auditing industry, as well as in enabling stakeholder inclusiveness and the effectiveness of human rights impact assessments (Gray and Gray, 2011). In addition, accounting can help companies to bring into operation the due diligence requirements by providing measuring and reporting tools (Chetty, 2011). Similarly, Frankental (2011) underlines the opportunities that arise for corporate accounting from the business and human rights debate.

However, despite the wide recognition of the importance of human rights issues for the accounting community, there has been limited understanding of the issues in the accounting literature (Gray and Gray, 2011) and "the accounting profession and academia have largely been missing from the debate” (McPhail and McKernan, 2011). Many aspects remain to be examined and "it would be as yet premature to presume a human rights spring in accounting and finance” (Gray and Gray, 2011).

Based on the considerations above, the research questions this research attempts to answer are the following: Does accounting help companies in making their suppliers compliant with human rights requirements? How companies 
translate human rights requirements into accounting practices? What are the meaning of human rights in the reality of the actors that should comply to requirements?

\section{Methodology}

Among all the management accounting research paradigms developed in the literature, pragmatic constructivism seems to offer a sound paradigmatic base for understanding and explaining the validity of the existing accounting practices for human rights.

According to this paradigm, “management accounting and control only provide valid results in practice if they incorporate the four aspects of the world of human life-facts, logic, values and communication” (Nørreklit et al., 2006). Accordingly, this study proposes that human rights are the results of human values, they are embedded in human behaviour and they are expressed in human language. We then conclude that accounting must consider all these dimensions in his effort of describing, reporting, analysing situations where human rights violations occur or can occur.

Accounting information constitutes the base for action and accounting practice works if it translates theoretical knowledge into practice (Nørreklit et al., 2006). Therefore, accounting must reduce the gap between knowledge and doing, by translating the universal principles of human rights into accounting systems that have practical validity. The final output of accounting practice is a social construct that is a general condition for successful actions (Nørreklit et al., 2006). The application of this paradigm to the topic described above leads to the following research hypothesis:

1. The validity of accounting practice for human rights depends on its capability of integrating:

- Facts (e.g. what does the supplier do to respect human rights?);

- Values (e.g. what are the supplier motivations for respecting human rights?);

- Possibilities (e. g. which are the enablers/barriers for respecting human rights?);

- Communication (e.g. how does the company communicate its business topos for human rights to its suppliers?).

2. Companies need to enable a convergence between different topoi (the overarching company topoi and the overarching supplier topoi) in a meta-topos (“a common space of meaning” Nørreklit et al., 2011).

The final aim of accounting for human rights is to foster an intercultural dialogue between a company and its suppliers in which differences are dialectically overcome and common values are constructed. These theoretical conclusions need to be investigated in an empirical setting: "in order to understand the "logic" of the world we live in we need to immerse ourselves into the particularity of an empirical reality" (Cooper et al. 2011). Therefore, the aim of this research is the elaboration of a case study in which the accounting measures for making suppliers compliant with human rights requirements will be analysed using the pragmatic constructivist paradigm.

Given the exploratory nature of the research, we develop a plan of action open to new evidences and try to gain a deep understanding of the phenomena being investigated. Data will be collected through qualitative techniques such as focus groups, document/archival record analysis, interviews and direct observation. By means of interviews and focus groups, we try to reconstruct the overarching topoi of both the focal company and the company's supplier and then evaluate the contribution of values to the process of inter-subjective reality production by comparing these overarching topoi.

\section{Findings}

The research is ongoing. Results are expected to shows how a pragmatic constructivist perspective may help companies in operationalizing the human rights agenda. In particular, the research demonstrates that the pragmatic constructivist paradigm can reduce the knowledge-doing gap dominating the ongoing implementation of Ruggie's framework by providing an ontological and epistemological base for evaluating the validity of the existing accounting practices.

Furthermore, we would like to demonstrate the central role played by values in shaping a common understanding of human rights. Finally, this study should confirm that the existing accounting practices are unable to respond to the emerging agenda on human rights. This would be especially true when companies are held accountable for violation of human rights committed by their suppliers. 


\section{Discussion}

This study extends the existing research in many ways. Firstly, this paper contributes to the meta-theory of pragmatic constructivism by applying this paradigm to an interorganizational setting. Furthermore, this study discovers the ethical contribution of the pragmatic constructivist paradigm by focusing on the role of values in the construction of business reality.

Second, the contribution of this research lies in the development of a new conceptualization of human rights as "a social constructed realty". We show how the translation of their universal nature into empirical context is inevitably affected by social practices. In this perspective, the concept of human rights can play an important role in reinforcing or weakening the unequal power that lays the foundations of social domination. This study highlights that the challenge in accounting for human rights is the translation of universal principles of human rights into a social construct reality ensuing from an intercultural dialogue. In addition, we explore the topic of human rights in terms of practical validity, calling for an approach free from ideological assumptions.

Finally, this research enriches the previous studies on accounting and human rights by reading this topic in a supply chain perspective. Only recently, the potential role of management accounting in supply chain management has been investigated (Ramos, 2004). The vertical dimension of organizations has been for long time the prevalent unit of analysis in the accounting studies, to the detriment of a more integrated understanding of business relationships. In this context, accounting was conceived as a tool of hierarchical power management. An emergent literature on interorganizational controls has overcome this vertical imperative, denounced for the first time by Hopwood in 1996. Since then, the literature has dealt with the problem of analysing management processes in a supply chains perspective.

However, as underlined by Caglio and Ditillo (2008), most of the studies continue to fail in adopting a real network perspective by focusing in a subset of relationships. According to these authors, the development of alternative and combined control solutions can help in solving emerging control problems (such as cooperation, coordination and appropriation) and in avoiding the reductionism of simplified control archetypes.

Similarly to what happened in the field of accounting, despite sustainability and supply chain management are gaining an increasingly attention in the literature, applications of corporate social responsibility (CSR) to the supply chain have had little development (Maloni and Brown, 2006). In addition, the research on the topic appears dominated by environmental issues (Carter and Easton, 2011; Seuring and Müller, 2008; Ashby et al., 2012). Indeed, the social dimension is a largely unexplored issue in sustainable supply chain (Hall and Matos, 2010), especially with respect to human rights.

This study fills these research gaps by adopting an interdisciplinary approach and providing theoretical insights to help business practitioners to understand their own practices.

\section{Limitations and future research}

The focus is limited to an interorganizational perspective. Furthermore, although considering the interdimensional integration of the four dimensions of reality, the primary concern is to explore the value dimension as enabler for the construction of meta-topoi. Moreover, the findings of this research are not subject to scientific generalization and this can be reasonably considered a limitation of the study. However, this kind of generalization is not the desired output of the work. The leading objective of this research is to expand a theory (“analytic generalization”, Yin, 2009) for understanding and shaping practice.

The role played by values in shaping business practices requires further examination. Future researchers may test our findings within an intercultural comparative perspective or in specific organizational settings (e.g. hospitals, universities, prisons). Furthermore, the impact of human rights violation on the corporate accountability is an issue worth of deeper investigation.

As a final point, we believe that the exploration of new and multiple sources of data (e.g. pictures, videos, news) for case analysis is crucial to the advancement of this paradigm of research. 


\section{Originality}

Human rights management is a new challenge that companies need to face to gain accountability in today's society. This study attempts to respond to the emerging agenda on human rights by adopting a developing paradigm, the pragmatic constructivism. The originality of this study concerns the development of an unexplored ethical understanding of this paradigm. Indeed, our study tries to explore the value dimension as expression of an ethical approach to action and as an ethical understanding of facts and possibilities. In so doing, we attribute a moral significance to values and we open the discussion of pragmatic constructivism to other stimulating research perspectives. Furthermore, this study differs from previous studies insofar as it offers a theoretical tool to assess the validity of the existing accounting practices for human rights. 